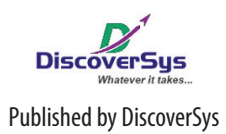

Published by DiscoverSys

\section{Prostitution Legislation Reforms in Western Australia: What Indonesia Can Learn}

\author{
Komang Ayu Kartika Sari*
}

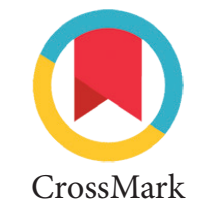

Department of Community and Preventive Medicine, Faculty of Medicine Udayana University
*Correspondence to: Komang Ayu Kartika Sari, Department of Community and Preventive Medicine, Faculty of Medicine Udayana University ayoex_11@yahoo.co.id

\section{INTRODUCTION}

Prostitution is still a complicated problem worldwide including in Western Australia. It is estimated that there are 1700 sex workers and 38 identified brothels in Western Australia ${ }^{1}$ and prostitution legislation is still an ongoing debatable issue in the state. There has been a significant change in prostitution laws and enforcement practices, which is due to the rising worldwide problem of sex trafficking and its relation to prostitution. ${ }^{2}$ The Liberal or National Government of Western Australia planned to introduce the prostitution legislation reforms, which were intended to make brothels to be the "only viable" and legal workplaces for sex workers, to make sex workers have no opportunity to work privately in residential areas and to force them to work for the third parties or to relocate them to industrial areas. ${ }^{3}$ It would be implemented through a brothel licensing policy, which in turn will make non brothel-based sex workers considered illegal. Brothels are indeed more organized and easier to provide health care and education than the street ${ }^{4}$ and based on research in the Norwegian capital, ${ }^{5}$ an existing law can make people have more negative attitudes towards buying sex. However, particular form of regulation and practice may result in worse situations and can undermine the health and wellbeing of sex workers. This article will discuss in details why the prostitution legislation reforms released by The Liberal/National Government in WA should not be fully supported and what we can learn based on the context of Indonesia.

\section{DISCUSSION}

According to Donovan et al. (2010), ${ }^{6}$ licensing of sex workers should not be considered as an appropriate legislative response and it has consistently failed for a long term of period. As a result, most premises and prostitutes remain unlicensed and there is still a potential of police corruption because the criminal codes are still in force. As the example is the case in Queensland, where there are only $10 \%$ of brothels that have been licensed under the scheme. ${ }^{7}$ In addition, licensing systems are expensive and have potential to emerge many unlicensed subgroups that usually avoid surveillance and public health services, hence, can bring a potential threat to public health. ${ }^{6}$

The regulation of "prostitution free zones" in residential areas and the brothels licensing policy may enforce expansion of sex workers to remote or unsafe areas. ${ }^{8}$ Although legalisation through a licensing policy is intended to reduce expansion of sex industry, an experience in Victoria ${ }^{9}$ showed that it has resulted in massive expansion. There is a significant increase in the number of legal and illegal brothels and the amount of money spent for prostitution among Victorian men. In addition, the demand for high risk sexual practice (anal intercourse and anal play) has been shown to increase particularly in licensed brothels. ${ }^{10}$ Australian Sex Workers Association, ${ }^{3}$ suggests that if this government proposal is successful, it would be the first time in Western Australia that most sex work of consenting adults will be illegal, except the sex work in the few licensed premises in the industrial areas.

Furthermore, people working in the licensed brothels will be registered, entitle them as identified sex workers and may put their family, future employment and safety at risk. ${ }^{3}$ The information gained for the licensing purposes will remain even after they leave the industry, and this effect will be their lifetime experience. It was also argued that many sex workers will have no option other than working at unlicensed brothels and the regulation will highly cost the WA community due to the excessive cost of compliance and operation. ${ }^{3}$ Health promotion is one of the sectors that will be affected because non-compliant premises and unlicensed prostitutes tend to avoid detection.

The legislation reforms also mentioned that only permanent residents and citizens will be able to get the license. This regulation may have a significant impact to sex workers in WA since almost $50 \%$ of all sex workers in Perth were not born in Australia. ${ }^{6}$ According to the study conducted in France ${ }^{11}$ the denial of foreign sex workers can make them treated as minors who are not able to have a choice for their life. They may also be forced to go back to their country of origin or to return underground by using the ambiguous compassion towards them.

The other concerning part of the prostitution legislation reforms is the increase of police power to target the unlawful prostitution. A study conducted 
by Donovan et al. ${ }^{6}$ found that there are more women in Perth than the other two cities in the study who had direct experiences with police and more likely to report more police visits to their workplace. Even though many sex workers said that the police were supportive and friendly, some women reported violence and physical assaults. The increase of police power in dealing with prostitution may lead to human rights violations such as physical assault, mandatory HIV testing, charges for the transmission of HIV and other sexually transmitted infections, and breaches of confidentiality. ${ }^{8}$ This approach may need to be redirected to decriminalisation system as implemented in Queensland, which has been documented to improve protection and to advance sex workers' rights. The opportunity to work legally and decriminalised can enable sex workers to report violence to the police, whose role can be turned into ensuring workers' safety rather than arresting and harassing them. ${ }^{2,12}$

It has been observed in a study ${ }^{13}$ that criminalisation is not an effective public health effort for HIV prevention. In fact, it will not decrease HIV transmission, and even worse, criminalising prostitution will put the issue underground. It is recommended that decriminalisation system should be applied with the details including the needs for health departments and HIV related organizations to provide accurate information for HIV positive sex workers and to improve health policies to reduce stigma. Additionally, State and Territory Government need to decriminalize sex workers who are living with HIV, develop consistent legislation for sex workers with HIV, and introduce the anti-discrimination laws for all sex workers. Based on the above justification, prohibition of commercial sex works when a person is infected with HIV or the other sexually transmitted infections is another element in the reforms that still needs our attention.

According to Csete and Cohen, ${ }^{8}$ the criminalised status of the illegal sex workers may also lead to the abusive and judgmental services in the health system, which will have a significant effect on their health. A study conducted in San Fransisco ${ }^{14}$ also found that legalisation would not always reduce the stigma of prostitution as there is already a deep cultural belief regarding sex work. It is recommended that government needs to ensure safety and legal protection for sex workers that are the same as for the other workers. An experience in New Zealand showed that decriminalization of sex workers will increase their safety and support their rights. ${ }^{15}$ It is also suggested by Butcher ${ }^{16}$ that participation of sex workers in HIV prevention efforts can be expected through supports from public health professionals in terms of their rights and safety.

\section{CONCLUSION}

It can be seen that some points in the WA prostitution legislation reforms still need further consideration, as they have potential to undermine the health and safety of sex workers. The reforms provide the idea of legalising sex work in WA; however, some points are still conflicting with the idea of decriminalisation of sex work. Some studies and experiences in implementing legalisation through a licensing system policy indicated that this system has failed in facilitating sex workers' needs and human rights in the sex industry. The increase of police power in dealing with incompliance of sex workers may also lead to human rights violations including physical assault and breaches of confidentiality. Stigma and discrimination towards foreign sex workers and sex workers with HIV were the other concerning parts of the reforms which require changes.

The proposed approach in prostitution in WA needs to be redirected to decriminalisation system with the implementation of harm reduction to achieve the effective public health efforts. Intensive health promotion efforts, including accurate information for HIV positive sex workers and health policies to reduce stigma and discrimination for all sex workers are needed to provide supportive environment for sex workers, which will enable their health and safety issues to be addressed. These approaches should be applied in the Indonesian context as well, where sex workers are still illegal and mostly criminalised. Decriminalisation system is needed even when there is no idea of legalising prostitution yet in Indonesia. In addition, as brothelbased sex workers are more organised and easier to reach, they have higher potential to participate in the health promotion efforts. The established brothels in Indonesia therefore should be well managed in terms of health and safety in the premises, without any human rights violation and criminalisation.

\section{REFERENCES}

1. Porter C. Prostitution Legislation Reform. Hansard; 2010.

2. Weitzer. Legalizing Prostitution. The British Journal of Criminology 2009; 49(1):88.

3. Scarlet alliance. Whose safety? Regulation of the sex industry in Western Australia. HIV Australia 2010; 8(4): 24-26.

4. Harcourt C. \& Donovan B. The many faces of sex work. Sexually Transmitted Infections 2005; 81: 201-206.

5. Kotsadam A, and Jakobsson. Do laws affect attitudes? An assessment of the Norwegian prostitution law using longitudinal data. International Review of Law and Economics 2011.

6. Donovan BC. Harcourt S. Egger K. Schneider J. O'Connor L. Marshall MY. Chen, and Fairley. The Sex Industry in Western Australia. 2010. Available from: http:// www.nchecr.unsw.edu.au/NCHECRweb.nsf/resources/ SHPReport/\$file/WASexReport.pdf 
7. Prostitution Licensing Authority. Annual Report 20092010. Available from: http://www.pla.qld. gov.au/ Resources/PLA/reportsPublications/annualReport/2010/ documents/Annual\%20Report\%202009-2010.pdf.

8. Csete, J. and Cohen. Health Benefits of Legal Services for Criminalized Populations: The Case of People Who Use Drugs, Sex Workers and Sexual and Gender Minorities. The Journal of Law, Medicine \& Ethics 2010; 38(4): 816. http://proquest.umi.com. dbgw.lis.curtin.edu.au/pqdweb? $\mathrm{did}=2234897781 \& \mathrm{Fmt}=$ 7\&clientId $=22212 \& \mathrm{RQT}=309 \& \mathrm{VName}=\mathrm{PQD}($ accessed 21 April 2011).

9. Mary Lucille and Sheila. Legalization: The Australian experience. Violence Against Women 2002; 8(9): 1140.

10. Seib CM, Dunne J, Fischer and Najman. Commercial Sexual Practices Before and After Legalization in Australia. Archives of Sexual Behavior 2010; 39(4): 979.

11. Mathieu L. Neighbors' anxieties against prostitutes' fears: Ambivalence and repression in the policing of street prostitution in France. Emotion, Space and Society 2011.

12. Sullivan B. When (Some) Prostitution is Legal: The Impact of Law Reform on Sex Work in Australia. Journal of Law and Society 2010; 37(1): 85.
13. Jeffreys E, Matthews, and Thomas. HIV criminalisation and sex work in Australia. Reproductive Health Matters 2010; 18(35): 129-136.

14. Lutnick A, and Cohan. Criminalization, legalization or decriminalization of sex work: what female sex workers say in San Francisco, USA. Reproductive Health Matters 2009; 17(34):38-46.

15. Melissa F. Bad for the body, bad for the heart: Prostitution harms women even if legalized or decriminalized. Violence Against Women 2002; 10(10): 1087.

16. Butcher, K. Confusion between prostitution and sex trafficking. The Lancet 2003; 361(9373): 1983.

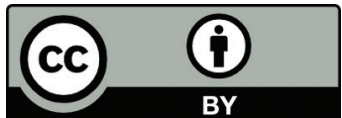

This work is licensed under a Creative Commons Attribution 